\title{
Violência e Saúde: Concepções de Profissionais de uma Unidade Básica de Saúde
}

\author{
Violence and Health: Conceptualizations by \\ Professionals from a Primary Healthcare \\ Service
}

\author{
Cristiano Claudino Oliveira \\ Margareth Aparecida Santini de Almeida \\ Ione Morita
}

\section{PALAVRAS-CHAVE: \\ - Violência \\ - Profissional de Saúde \\ - Atenção Primária à Saúde \\ - Educação em Saúde.}

\section{KEYWORDS:}

- Violence

- Health Care Professional

- Primary Health Care

- Health Education.

Recebido em: 02/12/2010

Aprovado em: 28/04/2011

REVISTA BRASILEIRA DE EDUCAÇÃO MÉDIC

Introdução: A Organização Mundial da Saúde (OMS) e o Ministério da Saúde (MS) brasileiro definem violência como fenômeno multicausal, de múltiplas manifestações, cujas consequências afetam também o setor da saúde. Objetivos: Identificar concepções dos profissionais de uma Unidade Básica de Saúde (UBS) sobre violência. Métodos: A metodologia desenvolvida foi qualitativa, identificando-se as representações sociais sobre violência. Realizaram-se 17 entrevistas semiestruturadas, audiogravadas, cujo conteúdo foi analisado pela identificação de núcleos recorrentes nas falas dos sujeitos. Resultados: Independentemente da formação, os profissionais reconheceram a pluralidade da violência, destacando suas manifestações, revelando, porém, despreparo para sua abordagem, reflexo da formação fundamentalmente biomédica. A violência, nessa comunidade, é subnotificada, pois a população é intimidada pelo problema, e o profissional não consegue abordá-lo. Conclusão: A violência subnotificada nessa localidade representa um microcosmo das fragilidades do sistema de saúde na capacitação de profissionais e assistência multidisciplinar, justificando a inserção da temática da violência na agenda da saúde pública.

\section{ABSTRACT}

Introduction: The World Health Organization (WHO) and the Brazilian Ministry of Health define violence as a multi-causal phenomenon with multiple manifestations whose outcomes affect the healthcare sector, among others. Objectives: The study aimed to identify perceptions of violence among professionals in a primary healthcare service. Methods: The methodology was qualitative, identifying social representations of violence. Seventeen semi-structured interviews were conducted and audio-taped. The content was analyzed for recurrent core themes in the subjects' statements. Results: Regardless of their training, the professionals acknowledged the plural nature of violence and emphasized its manifestations. However, they displayed a lack of preparedness to deal with violence, thus reflecting their essentially biomedical training. Violence in the community in question is underreported, since the local population is intimidated by the problem, and health professionals are unprepared to deal with it. Conclusion: Underreported violence in this community reveals weaknesses in the healthcare system to train professionals and organize multidisciplinary care, thus justifying the inclusion of violence on the public health agenda. 


\section{INTRODUÇÃO}

A Organização Mundial da Saúde (OMS) e o Ministério da Saúde (MS) definem a violência como um fenômeno multicausal, de múltiplas manifestações e naturezas, epidemiologicamente importante e que requer uma abordagem específica de seus fatores e contextos ${ }^{1}$. Suas consequências afetam de maneira ampla a sociedade, os indivíduos e também o setor da saúde, com imposição de novos problemas para o atendimento médico ${ }^{2,3}$.

A violência representa, atualmente, um importante desafio para os profissionais do setor da saúde, uma vez que a organização de seus atendimentos está centrada num modelo biomédico, marcado por uma lógica de relações muito lineares de causa e efeito entre os fenômenos, pouco aproveitável para o problema em questão. A violência se expressa como uma epidemia social que rejeita o modelo biomédico, cujo conhecimento é focado em intervenções técnicas circunscritas às doenças estudadas. A violência é complexa, suas causas e efeitos estão integrados num sistema de mútuas influências, restringindo oportunidades de medicalização desta temática. Essa problemática representa um complexo obstáculo no cenário da educação médica, pois a formação de profissionais de saúde preparados para enfrentar as variáveis envolvidas na questão da violência exige modelos de ensino que contemplem a saúde em seu sentido biológico, social e psíquico, de modo integrado e prático ${ }^{4}$.

Neste contexto, o presente trabalho objetivou identificar a concepção dos profissionais de uma Unidade Básica de Saúde (UBS) sobre a questão da violência. Além disso, buscou-se identificar estratégias de conduta desses profissionais na abordagem da violência, investigando-se dificuldades e facilidades existentes no enfrentamento desse problema, bem como identificar contatos prévios com a temática na trajetória de vida pessoal e profissional.

O estudo desenvolvido é uma ampliação de um trabalho sobre a temática violência e saúde iniciado no Programa Interação Universidade-Serviço-Comunidade (Iusc), mantido como disciplina na estrutura curricular do curso de Medicina na Faculdade de Medicina de Botucatu (FMB), da Universidade Estadual Paulista (Unesp) ${ }^{5}$. Dentre as várias UBS do município de Botucatu (SP), a área escolhida para o estudo aqui apresentado foi um dos territórios de ação do Programa Iusc.

\section{METODOLOGIA}

\section{Cenário do Estudo}

A área de abrangência estudada é uma região urbana periférica com 9.129 habitantes, mais de 50\% representados pelo sexo feminino. Quanto aos indicadores de saúde, observa-se uma taxa de mortalidade infantil $(16,8 \%$ ) um pouco superior à do município $(12,8 \%$ ), resultado próximo ao dos bairros formadores dos bolsões de pobreza da localidade. Ressalta-se também que, na faixa etária de 20 a 49 anos (adultos jovens e adultos), a mortalidade proporcional é maior na área de abrangência em foco $(22,6 \%)$ do que no município (13,1\%) no período de 2003 a $2007^{6}$.

\section{A Abordagem Qualitativa}

O trabalho utilizou a metodologia qualitativa por suas características de abertura, flexibilidade e capacidade de observação e interação com os atores sociais envolvidos nas temáticas focalizadas no estudo. A metodologia qualitativa explora o universo de significados, motivos, aspirações, crenças, valores e atitudes, um espaço profundo que não pode ser reduzido à operacionalização de variáveis. Neste sentido, buscaram-se as representações sociais sobre violência, entendidas como sistemas de interpretação que regem a relação dos sujeitos com o mundo e com os outros, sendo resultados de ideias socialmente reproduzidas e/ou de modificações ocorridas por intervenções históricas e sociais. Assim, a representação social, no contexto da pesquisa qualitativa, é a representação da construção da realidade, ultrapassando o próprio indivíduo, revelando a existência de fenômenos coletivos ${ }^{7}$.

Para isso, foi utilizado o recurso da entrevista audiogravada, sendo o discurso do entrevistado, após transcrição ipsis litteris, analisado por meio da identificação de núcleos recorrentes nas falas dos sujeitos, buscando a explicitação dos conteúdos e a compreensão das representações sociais, com obediência à similaridade dos significados, critério-base para agrupar os temas neste estudo.

As entrevistas foram realizadas pelo próprio pesquisador, que utilizou um roteiro de perguntas semiestruturadas, de modo que cada entrevistado respondesse aos questionamentos com liberdade de fala. $\mathrm{O}$ roteiro era um guia para o diálogo, dividido em quatro partes: identificação, formação, conhecimento sobre a comunidade, e violência e saúde. Foram entrevistados os 17 profissionais de saúde da UBS: uma enfermeira, dois médicos pediatras, dois médicos ginecologistas/ obstetras, um médico clínico, dois técnicos de enfermagem, um auxiliar administrativo e oito auxiliares de enfermagem.

As entrevistas foram divididas em dois grupos para facilitar a justaposição e a comparação de informações pela homogeneização das categorias dos entrevistados. Denominou-se Grupo $1(\mathrm{G} 1, \mathrm{n}=6)$ os profissionais com curso superior na área de saúde (um médico clínico, dois médicos pediatras, duas médicas ginecologistas/obstetras, uma enfermeira). Denominou-se Grupo $2(\mathrm{G} 2, \mathrm{n}=11)$ os profissionais com capaci- 
tação de cursos técnicos/curso superior fora da área de saúde (oito auxiliares de enfermagem, dois técnicos de enfermagem e um técnico administrativo). Trechos das entrevistas foram transcritos aqui para exemplificação, sendo marcados com a letra "E" seguida de numeração.

O estudo obteve aprovação do Comitê de Ética em Pesquisa da FMB/Unesp e da Secretaria Municipal de Saúde do município de Botucatu (SP).

\section{RESULTADOS E DISCUSSÃO}

\section{Identificação}

Foram entrevistados 17 profissionais de saúde, sendo a maioria, $13(76,5 \%)$, do sexo feminino. A média de idade registrada foi de 38,47 anos (variação: 26-54 anos). Nenhum dos entrevistados reside atualmente no bairro e 12 (70,6\%) trabalham nesta Unidade há menos de cinco anos. Apenas um profissional (do Grupo 2) relatou ser sua primeira experiência em Atenção Primária à Saúde. Três profissionais referiram experiência prévia também em Unidade de Saúde da Família (USF). Já oito entrevistados compartilhavam atuações também nos níveis secundário e terciário da saúde.

\section{Sobre a formação}

O objetivo era reconhecer elementos de formação do profissional de saúde que atua na UBS, englobando inclusive possíveis contatos com a questão da violência em sua trajetória de vida pessoal, em empregos anteriores ou mesmo durante os cursos formativos.

$\mathrm{Na}$ trajetória profissional, todos os profissionais de G1 tiveram algum contato com a questão da violência, a maioria em serviços de urgência/emergência, raramente em cenário da Atenção Primária à Saúde.

"Em relação a posto de saúde, não. Em pronto-socorro, sim. Em Unidade Básica, não, mas em pronto-socorro tem caso de agressão, paciente mais agressivo, mais nesse sentido." (E12)

Em G2, nove profissionais relataram contato com a violência, prevalecendo o envolvimento indireto, isto é, os casos chegaram até eles por meio da família ou comentários de colegas de trabalho.

Para ambos os grupos de profissionais, as formas de violência citadas são similares: doméstica, de gênero e infantil. A diferença está na qualificação do contato, subordinada à própria atuação do profissional.

$\mathrm{Na}$ trajetória de vida pessoal dos profissionais de ambos os grupos, são localizadas vivências com formas de violência, principalmente doméstica, incluindo relatos de indivíduos vítimas de agressões físicas na infância.
As situações pessoais e profissionais de violência influenciam positivamente a aprendizagem da temática por esses indivíduos, já que em seus relatos sobre os aspectos formativos da questão nota-se carência de informações a respeito da violência.

Em G1, a enfermeira, em sua graduação, teve uma aula expositiva com essa temática. Já entre os médicos entrevistados, houve consenso de que o tema violência é pouco abordado na graduação, porque não é enfocado academicamente nos currículos das escolas médicas. Ressaltam-se, no discurso, as formas pontuais de abordagem da temática em disciplinas relacionadas à saúde mental, à saúde da mulher e à medicina de urgência. Segundo os médicos, a principal fonte de aprendizado desse assunto é a vivência prática da situação, que ocorre efetivamente na residência médica.

"Durante a graduação, não, muito pouco. Possivelmente, teve aí uma falha de currículo, nós não tivemos isso. Mas durante a residência, aprendi basicamente coisas para detectar $O$ problema (a violência) nos pacientes." (E14)

"[...] enfim, em nossa graduação, em nossa formação, a gente não tem nenhuma informação de como lidar com isso, está meio complicado. [...] É pela vivência nossa de saúde, de cuidado mesmo, [...] e aos poucos você acaba formando, você mesmo, uma maneira de lidar com isso (a violência)." (E15)

O problema da formação é verificado também em G2, pois a maioria afirmou nunca ter recebido curso ou aula sobre essa temática, nem durante a formação, nem durante o ingresso no mercado de trabalho. As poucas abordagens foram cursos pontuais durante o período de trabalho no Programa Saúde da Família ou aula/discussão baseada numa visão acadêmica do assunto. Observa-se discreta tendência para abordagem da questão focada em condutas diante do caso, com menos ênfase nas estratégias de identificação de possíveis vítimas dessas situações.

Os profissionais de G1 e G2 valorizaram a vivência prática para o aprendizado da temática, entretanto o olhar dos entrevistados do primeiro grupo é focado na técnica/intervenção, enquanto o outro grupo está direcionado à escuta do paciente.

Os profissionais de saúde, de forma geral, apresentam dificuldades em trabalhar com problemáticas que envolvam a violência, independentemente de terem cursado ensino superior ou técnico, pois a formação é centrada na visão biomédica, priorizando intervenções técnicas e cultuando uma lógica curativa que não contempla a complexidade da temática violência. O indivíduo, portanto, sai do seu período de formação diretamente para o mercado de trabalho, sem o entendimen- 
to do universo da violência, e, em sua prática, percebe que o tema não é passível de medicalização, sendo necessárias outras estratégias que lhe garantam acesso a essa problemática ${ }^{4}$.

A precariedade da formação profissional de saúde no campo da violência também se reflete no fato de muitos se reconhecerem despreparados para esse tipo de situação. Segundo Souza et $a l .{ }^{8}$, há necessidade de uma formação socialmente contextualizada, com ensino, trabalho e realidade plenamente articulados, instrumentalizando os profissionais em formação para o enfrentamento de problemas e necessidades reais da população, como no caso da violência ${ }^{8}$. Neste contexto, valorizam-se estratégias de ensino do tema violência por meio de sua inserção nos currículos e também nas capacitações de docentes, com a criação de campos de estágios para vivência da questão e até mesmo materiais didáticos voltados à preparação teórica $\mathrm{e}$ prática para esse assunto ${ }^{4,8}$. Ressalta-se também a necessidade de atualização contínua dos profissionais de saúde já inseridos no mercado de trabalho, por meio de estratégias de educação permanente em saúde, visando capacitação fundamentada em reflexões sobre suas práticas, ferramentas técnico-científicas e diálogos com a comunidade e a equipe de trabalho ${ }^{9}$.

\section{Sobre a Comunidade}

Nesse aspecto, visou-se entender o relacionamento entre UBS e comunidade, acreditando que a boa conexão entre esses universos favoreceria o enfrentamento da violência.

A fala da enfermeira, em G1, é importante para caracterizar a relação entre comunidade e serviço de saúde, já que a profissional afirmou dificuldade no planejamento de ações na área de abrangência, pois a própria unidade não conhece verdadeiramente sua população, prevalecendo o desconhecimento mútuo entre ambos. O restante dos membros do grupo reafirmou a participação limitada da unidade nesta comunidade, sobretudo pelo pouco envolvimento da população, justificativa também adotada por G2. As tentativas frustradas na construção de grupos de pacientes são usadas como exemplos da desconexão entre unidade e comunidade.

Os profissionais de G2 citaram aspectos para aprimorar a relação entre os dois polos: desenvolvimento de espaços de fala e escuta entre pacientes e também entre os funcionários; ampliação dos recursos financeiros; capacitação profissional; e planejamento de intervenções com foco nas demandas reais. Uma fala bastante representativa desse ponto de vista é a do entrevistado E6:

"Eu acho que quando se têm mais recursos, poderia se ter mais participação, mas a gente não tem recurso para participar mais. Para conhecer mais o bairro, precisa ter mais re- curso, ter mais gente, ter mais capacitação; então eu acho que não é mais participativa porque não se tem mais recurso, não se tem mais gente [...] você não tem como ir na casa deles, conhecer as necessidades deles, mas não dar nada em troca, eles não querem apenas que você conheça a realidade deles [...] não tem como você saber o que pode dar espaço a uma violência, a uma necessidade [...] e simplesmente só saber o que acontece e não dar um suporte. Então não tem como só saber o que acontece e não ajudar... Então, teria como participar mais, mas se tivesse suporte para isso." (E6)

Os entrevistados de G1 referiram bom nível de reconhecimento das demandas locais, sendo a principal fonte de informação os próprios pacientes, pois não haveria tempo suficiente para outras estratégias. A estrutura da Unidade também foi questionada por não promover reuniões para discussão das informações apreendidas pelos diferentes profissionais durante as consultas. Outras fontes citadas para o reconhecimento das demandas locais foram visitas realizadas pela própria Unidade, exploração do bairro a pé, por meio de alunos que realizam atividades curriculares na UBS, contato com funcionários e assistente social, e a própria mídia.

Nas falas dos profissionais de ambos os grupos, verifica-se conhecimento restrito dos problemas da comunidade, formulado basicamente pelo que é trazido à Unidade, o que dificulta a aproximação entre Unidade e comunidade:

\footnotetext{
"A gente tem uma noção de como é essa comunidade pelo contato do dia a dia com os pacientes. Só não tem uma reunião para a gente passar para os funcionários como é essa comunidade, quais as necessidades dela, como ela interage, não, não tem nada disso." (E15)

"[...] O que eu conheço do paciente é o que ocorre da porta para dentro da comunidade. É mais por paciente que vem contando, porque aqui a gente não tem muito contato com a comunidade fora da Unidade. [...] é um relacionamento estritamente profissional." (E9)
}

O contexto dessa Unidade revela um modelo de saúde centrado na resolução curativa. A UBS não ultrapassa seus limites de atuação técnica, desfavorecendo a formação de vínculos, compondo uma organização frágil para o enfrentamento da violência, não suprindo sua pluralidade de causas e efeitos. Observa-se também um processo de culpabilização da comunidade e da carência de agentes de saúde como justificativa dessa realidade.

Os agentes de saúde, personagens comuns no Programa Saúde da Família, têm sua importância como elo entre as necessidades de saúde da população e as intervenções para me- 
lhorar suas condições de vida. Na problemática da violência, eles seriam úteis na identificação de situações de risco e no encaminhamento à Unidade, entretanto a literatura ${ }^{10}$ também expõe sua limitação, enfocando a formação desses agentes. Eles estão próximos da comunidade, mas precisam de capacitação para exercer vigilância e identificar casos suspeitos ${ }^{10}$. Indubitavelmente, esses agentes, quando bem preparados, ganham um "olhar sensível" em seus laços com a população, promovendo prevenção, identificação e intervenção nas situações de violência, especialmente familiar ${ }^{11}$.

Todos os profissionais entrevistados de G1 e a maioria de G2 afirmaram que a violência é um problema presente nessa comunidade. Ressalta-se, inclusive, a visão de sua subnotificação porque a população procura o nível terciário de atenção à saúde ou delegacias de polícia. A UBS, segundo eles, não é procurada, pois os pacientes têm preocupação especial na manutenção do sigilo desses fatos. Essa constatação reflete a importância da busca ativa desses casos durante as consultas, com espaços de diálogo, bem como de seu acompanhamento com psicólogos e assistentes sociais.

“Não é um assunto explicitamente comentado. É um assunto que você chega a ver, mas, 'ah, será?'. Porque na maioria das vezes, quando acontece isso, o paciente, ele se retrai, praticamente, eu nunca vi ninguém aqui com olho roxo, hematoma, nada disso, se acontece uma situação dessa, a pessoa, ela vai falar 'eu bati, eu caí e machuquei'." (E12)

"Existir, existe... Mas não chega para gente. [...] Não vem aqui não, não chega para gente não. [...] Se você tem um problema de violência, muitas vezes você quer esconder. [...] Vergonha, medo do que pode acontecer, as pessoas têm uma informação muito errada das leis." (E17)

Para G1, as formas de violência mais vivenciadas pela comunidade seriam: tráfico de drogas, violência contra a criança, violência doméstica, violência verbal/psicológica, violência relacionada à presença de presidiários na família, violência na relação paciente e sistema de saúde. Em G2, notam-se manifestações de violência na forma doméstica, na violência contra a mulher e contra a criança, com importante influência de álcool e drogas.

A relação da juventude com o tráfico de drogas é mencionada como uma realidade existente e não questionada, uma vez que a comunidade local já teria se acostumado, já faz parte da história do bairro uma trajetória de violência iniciada no passado.

“Eu acho que não muda mais. Eles já se acostumaram. Nada mais é anormal. Está tudo normal, eles estão passando e eles estão fumando, estão se drogando, para eles está tudo normal, acaba sendo normal do ponto de vista que a gente não pode se intrometer, a gente não pode fazer nada." (E8)

A questão do tráfico de drogas é preocupante, principalmente pelo envolvimento de adolescentes. Estudos da Organização Internacional do Trabalho (OIT) apontam queda na média de idade dos jovens que ingressam no tráfico. Na década de 1990, a faixa de idade era de 15 a 16 anos, e a partir do ano 2000 essa média passou a se situar entre 12 e 13 anos. Os principais fatores que motivam os jovens a ingressar no tráfico de drogas são a perspectiva de ganhos econômicos e desejo de bens de consumo ${ }^{12}$.

A violência doméstica é entendida como toda ação ou omissão que prejudique o bem-estar ou a liberdade e o direito ao pleno desenvolvimento de um membro da família. As principais vítimas da violência doméstica são as mulheres, as crianças e os idosos ${ }^{13}$. No caso da violência contra a mulher, estudo de Schraiber et al. ${ }^{14}$ com 3.293 usuárias do sistema de saúde do município de São Paulo apontou que 55\% delas tiveram pelo menos um episódio de violência física ou sexual na vida promovido por algum parceiro ${ }^{14}$. Os reflexos da violência doméstica são percebidos pelo sistema de saúde pelos custos ou complexidade do atendimento que representam. Apesar do importante papel do setor de saúde neste tipo frequente de violência, os profissionais tendem a subestimar essa realidade, voltando-se prioritariamente para a pesquisa de injúrias físicas e pouco se empenhando na prevenção ou diagnóstico das origens daquelas lesões ou mesmo se tais ferimentos mascaram agressões psíquicas ${ }^{13}$. Acredita-se que essa atitude seja consequência de falhas formativas, como sugere estudo recente de Vicente et al. ${ }^{15}$, trabalhando apenas com o conhecimento da questão da violência de gênero entre estudantes de Medicina e médicos residentes. Somente $24 \%$ de seus entrevistados tiveram alguma aula sobre o tema durante a graduação, porém é relevante o dado de que $89 \%$ deles julgam pertinente ao médico a investigação a respeito de violência durante a consulta. Assim, há empenho do profissional, mas ele carece de capacitação para realizar de modo correto essa abordagem ${ }^{15}$.

A violência que envolve o sistema de saúde, também lembrada pelos entrevistados, expõe profissionais e serviços de saúde, de forma geral, em posições ambivalentes. A Unidade, representante do serviço violenta a comunidade quando não consegue atender a todos, quando não pode ofertar todos os recursos diagnósticos e terapêuticos ou ainda quando não se organiza adequadamente para reconhecer as demandas da área de abrangência. Simultaneamente, essa mesma Unidade é violentada por aqueles cidadãos que tentam exigir seus di- 
reitos ou que são vítimas de outras agressões sociais e partem para o serviço com a mesma agressividade. Uma sociedade acometida pela pluralidade da violência se torna ansiosa e agressiva, e acaba se chocando com profissionais de saúde que também vivem no seu limite, na carência de recursos e capacitação. Assim, o serviço dessa Unidade é o microcosmo do panorama nacional da maioria das relações entre comunidade e serviços de saúde 4 .

Mesmo com os problemas de compreensão mútua entre comunidade e UBS, cinco entrevistados de G1 disseram considerar que a população confia no serviço com ressalvas, mas em relação ao objeto da confiança, que talvez esteja depositada no médico e não no serviço. Para um entrevistado, essa confiança inexiste, justificando-se pela própria questão da subnotificação dos casos de violência. Em G2, existe consenso de que a comunidade confia no serviço de saúde local, principalmente devido à grande demanda que a Unidade recebe e às poucas reclamações recebidas. Observam-se, novamente, olhares diferentes sobre o mesmo vínculo, já que os profissionais de G1 focam a relação médico-paciente e G2 destaca a relação serviço-comunidade.

Os comentários dos profissionais evidenciam ambiguidades na relação entre a população da área de abrangência e o serviço de saúde. Ao mesmo tempo em que a comunidade confia no serviço, ela não relata suas violências. Há confiança no serviço técnico da Unidade, mas não no posto de saúde como possível auxílio a sua situação. Aliados a isso, há fatores relacionados à vergonha e ao temor de que esse acontecimento negativo de sua vida seja partilhado com os demais membros da comunidade.

A relação entre uma Unidade e sua comunidade é complexa porque exige a formação de elos de confiança. Para que uma vítima de violência consiga extrapolar seus próprios preconceitos e relatar sua agressão, são fundamentais sólidas relações médico-paciente e serviço-paciente. Portanto, no caso da referida UBS, existem falhas formativas (dos profissionais de saúde) e estruturais que impedem um conhecimento mútuo entre as partes e dificulta que os casos cheguem à Unidade. Deeke et $a l .{ }^{16}$, ao realizarem pesquisa para saber onde as mulheres procuravam ajuda em casos de agressões, verificaram que o setor de saúde não foi citado por nenhuma delas. Os familiares $(33,3 \%)$ e nenhuma pessoa $(40 \%)$ foram os itens mais citados, dados confirmados por outras pesquisas nacionais ${ }^{16}$.

\section{Sobre Violência e Saúde}

O objetivo era reconhecer a concepção dos profissionais a respeito do conceito de violência e suas inter-relações com o campo da saúde.
Quanto à capacitação para enfrentar situações de violência, em G1, três entrevistados se consideraram preparados e três despreparados, norteados por enfoques diferentes. Os primeiros direcionaram o pensamento para o diagnóstico das situações de violência, numa visão técnica dessa realidade; os outros mantiveram uma visão mais abrangente, considerando as dificuldades na relação médico-paciente, no seguimento e acompanhamento desses casos. Sobretudo, independentemente das respostas, constataram-se dificuldades no manejo desses casos por não se sentirem capacitados para investigar e confirmar suas suspeitas de violência. Para isso, alegam a necessidade de expandir seus próprios conceitos de violência, ampliando-os para além da concepção física; e referem a necessidade da criação de espaços de diálogo entre os próprios profissionais e entre serviço e comunidade. Por fim, embora o diagnóstico seja realizado corretamente, relatam que o acompanhamento desses pacientes é bastante precário, dependendo de uma equipe transdisciplinar e atuante.

A sensação de despreparo para essas situações é mais evidente nas falas de G2, pois a maioria se considerou sem capacitação para lidar com casos de violência. Verificou-se, no grupo, ausência de capacitação para esse tipo de situação, evidenciando dificuldades na construção de vínculo com as vítimas e no acompanhamento desses pacientes.

O problema da violência pode passar silenciosamente pelos serviços de saúde, situação exemplificada pelos casos subnotificados, muitas vezes por motivos que a própria vítima da violência traz consigo. Entretanto, essa invisibilidade da violência perante os serviços de saúde também é construída graças ao despreparo dos próprios profissionais de saúde. Segundo Moreira et al..$^{17}$, os profissionais apresentam dificuldades no enfrentamento de casos suspeitos (identificação, atendimento, encaminhamento) bastante similares ao verificado no presente estudo. A maioria dos profissionais justifica seu próprio despreparo responsabilizando uma formação fragmentada, que inviabiliza a prática do acolhimento do indivíduo. Os profissionais egressos saem com forte tendência à medicalização e não conseguem promover abordagens psicossociais ${ }^{17}$.

Moreira et al. ${ }^{17}$ também ressaltam a importância do atendimento fundamentado numa relação solidária, respeitosa e acolhedora, buscando o estabelecimento de laços de confiança. Contudo, os autores não descartam a necessidade de um serviço ativo como pano de fundo. A relação médico-paciente é, antes de tudo, estabelecida com o serviço, com a Unidade, cabendo-lhe criar um ambiente propício ao diálogo, aproximando sua equipe da comunidade. E isso ocorre com a promoção de atividades educativas com a população, visando discutir a temática com moradores da área de abrangência, de 
modo que eles passem a confiar e a entender que tipo de colaboração os profissionais de saúde podem oferecer ${ }^{17}$.

Em ambos os grupos, a violência é encarada como problema de saúde pública, pois, afinal, o setor é uma linha quase obrigatória nos casos de violência, ainda que não diagnosticados por ele. Entretanto, outros elementos, como a educação, foram acrescentados no contexto, refletindo a natureza multicausal da violência, fenômeno de origem abrangente, entendido pelos entrevistados como uma questão social.

A saúde pública, conceitualmente, é a confluência de instâncias biológicas, sociais, comunitárias, políticas e econômicas no campo da saúde, permitindo realizações individuais e coletivas $^{18}$. Para Gomes et al. ${ }^{19}$, a inserção da temática violência no campo da saúde coletiva é uma necessidade para que se possa debater conhecimentos, práticas e políticas para esse problema $^{19}$, objetivando a melhora da qualidade de vida individual e coletiva ${ }^{20}$. A própria Organização Pan-Americana da Saúde (Opas) admitiu essa realidade, caracterizando a violência como endêmica e problema de saúde pública em vários países por causa do número de vítimas e da magnitude de suas sequelas orgânicas e emocionais ${ }^{21}$. Entretanto, cabe valorizar a perspectiva ampliada sobre a problemática da violência daqueles que a contextualizaram também em outros setores públicos.

A inclusão da violência no campo da saúde pública é o primeiro passo para o seu enfrentamento, pois essa área do conhecimento é uma articuladora interdisciplinar cujas ações podem ampliar a compreensão social da realidade e possibilitar melhorias nas condições de vida da sociedade no combate à violência social ${ }^{22}$. Esse diálogo entre as disciplinas, tão imprescindível, ainda está distante, exemplificando-se pela produção de conhecimento sobre a temática violência e saúde. Njaine et al. ${ }^{20}$ afirmam a necessidade de investimentos em pesquisas qualitativas, epidemiológicas e estudos longitudinais em nível nacional, enfatizando as peculiaridades culturais e sociais da questão da violência.

Quanto ao preparo das Unidades da Atenção Primária à Saúde, apenas um dos entrevistados de G1 manifestou que elas estariam preparadas para atender a esse tipo de demanda, do acolhimento ao seguimento do caso. Para o restante, a rede de Atenção Primária à Saúde não tem recursos humanos capacitados, nem estrutura suficiente para manejar essas situações. A opinião é compartilhada pela maioria dos entrevistados de G2, que expuseram a necessidade de equipe transdisciplinar atuante em toda a rede, em parceria com as Unidades, acompanhando psicossocialmente esses pacientes.

Em trabalhos realizados sobre violência doméstica no cenário da Atenção Primária à Saúde, as Unidades são conside- radas importantes sedes na detecção desse tipo de evento, por serem locais privilegiados para o desenvolvimento de ações de prevenção, reflexão e orientação sobre o tema, já que permitem contato mais próximo com os pacientes, possibilitando reconhecer e acolher incidentes mais graves ${ }^{23}$. Na comunidade analisada, essa proximidade foi considerada insuficiente, influenciando a maneira como os casos chegam à Unidade. O cenário é propício ao diagnóstico, mas é preciso considerar fatores relacionados ao paciente, ao próprio profissional e à estrutura do serviço para que efetivamente ele ocorra.

As potencialidades da Atenção Primária à Saúde englobam a perspectiva de abranger o problema desde o acolhimento e intervenção até a prevenção e promoção da não violência, numa abordagem integral do fenômeno da violência $^{23,24}$. Entretanto, as potencialidades da rede básica de saúde não são completamente praticadas no contexto da violência. A identificação do problema não deve ser o limite de atuação. A abordagem deve ser um processo contínuo, cujo resultado final seja a superação do problema pela paciente, com ajuda da Unidade. Nesse sentido, verifica-se a precariedade da rede social, que não cumpre seu papel de proteção às vítimas, sendo bastante difícil o acompanhamento psicológico, clínico e social desses pacientes ${ }^{23}$. A Atenção Primária à Saúde é, ainda, um espaço a ser aproveitado na promoção da interdisciplinaridade, visando à organização de estratégias que garantam os direitos das vítimas da violência e que promovam a cultura da não violência ${ }^{23,24}$.

\section{Concepções de Violência}

A formulação da ideia de violência é influenciada pelas vivências profissionais e pessoais de cada indivíduo. Ao contrário do esperado, as concepções de violência foram similares em ambos os grupos, mesmo com as diferenças de tempo e tipo de formação, o que reforça a influência das vivências e experiências durante a vida profissional na construção das ideias acerca desta temática. A carência de formação focada nesta área é um dado também importante, pois dificilmente esses entrevistados tiveram acesso à literatura específica sobre a temática para formular seus pensamentos. Talvez por isso suas definições englobem tipos de violência para poderem expressar sua multicausalidade.

A concepção apontada é ampla, com muitos significados e sentidos, em concordância com a definição da OMS. Em alguns momentos, os entrevistados fazem uma definição dicotômica: existe a violência física e um conjunto de outras violências, agrupadas e denominadas como violência não física. Em outros momentos, a justificativa para a definição aplicada envolve noções do conceito atual de saúde. As referências de 
violência mais citadas foram: "agressão não somente física" (dez citações), "verbal" (sete citações), "agressão física" (seis citações), "emocional/psíquica" (cinco citações), "contra a criança" (cinco citações), "ultraje à pessoa" (três citações), "violência social" (duas citações), violência contra a mulher (duas citações), "violência contra o sistema de saúde" (duas citações). Mesmo assim, em duas entrevistas, verificou-se que o conceito de violência ficou limitado apenas à esfera física, em dissonância com a OMS.

A literatura acredita que as práticas profissionais são influenciadas pelo modo como a violência é compreendida pelos indivíduos. O paciente "vítima de violência", em geral, não procura a Unidade motivado pela queixa do incidente. $\mathrm{O}$ profissional de saúde precisa incorporar a temática a sua consulta, ao seu cotidiano de atendimentos. É um desafio significativo, com interferências de sua concepção de violência ${ }^{21,22}$.

\footnotetext{
"Eu acho que tem vários sentidos. [...], eu acho que qualquer coisa que agride fisicamente, moralmente, socialmente uma pessoa é uma forma de violência." (E7)

"[...] quando se fala em violência, você pensa logo em violência física, mas eu acredito que a violência abrange muito mais que a violência, porque a pessoa pode não apanhar fisicamente, pode não ter marcas, mas às vezes a violência é emocional, ela é agredida emocionalmente." (E15)
}

\section{CONCLUSÕES}

A Unidade Básica de Saúde tem profissionais de saúde que em geral reconhecem a pluralidade do conceito de violência, citando suas diferentes formas para conceituar esse fenômeno, não existindo diferenças com relação ao nível educacional de cada um. De modo similar ao encontrado na literatura, referem dificuldades no enfrentamento dessa questão, muito fundamentadas em aspectos formativos, pois a temática é explorada de modo bastante precário nos cursos de graduação. Acredita-se ser necessária a inserção dessa realidade no currículo das escolas médicas brasileiras, uma vez que é epidemiologicamente marcante na sociedade, cabendo ao médico abordá-la biomedicamente e também socialmente. As necessidades formativas ultrapassam os limites das universidades e servem também para os cursos técnicos e para aqueles profissionais já fixados à rede pública de saúde, a fim de prepará-los para esse contexto.

Os profissionais de saúde entrevistados reconhecem o problema como questão de saúde pública, mas acreditam na responsabilização de outros setores públicos. Eles também denunciam a precariedade da rede social de apoio à Atenção
Primária à Saúde. Trata-se de um espaço com grandes possibilidades de atuação, numa abordagem integral da temática, mas que carece de profissionais capacitados, recursos financeiros e atuação integrada de assistentes sociais e psicólogos, fundamentais no acompanhamento dos pacientes.

Confirmou-se a presença da violência na área de abrangência como um fenômeno de natureza velada, que nem sempre alcança os profissionais da Unidade. Os fatores envolvidos estariam relacionados aos próprios pacientes, por seus medos diante da complexidade da questão, e também aos profissionais de saúde, formados num modelo de tendência à medicalização das situações. Neste contexto, é perceptível um importante distanciamento entre a comunidade e a Unidade. Foi relatada a necessidade da atuação de agentes comunitários de saúde na tentativa de reconhecimento do local, da população e de suas demandas. Acredita-se que seja uma iniciativa importante e que poderia melhorar o relacionamento entre essas duas instâncias. Valorizam-se, também, iniciativas como a do Programa Iusc, que busca uma formação médica socialmente contextualizada, levando a universidade e o estudante de Medicina para a comunidade, enxergando o paciente de forma global, além de sua morbidade.

Por fim, na comunidade de região periférica estudada, existe a presença da violência, porém ela é pouco diagnosticada pela Unidade Básica de Saúde local. Essa realidade é um microcosmo do que ocorre em outras regiões brasileiras, uma vez que a abordagem multidisciplinar desse assunto ainda é bastante precária, carecendo de investimentos do setor público, impulsionado pela inserção dessa temática na agenda da saúde pública.

\section{REFERÊNCIAS}

1. Minayo MCS. A violência dramatiza causas. In: Minayo MCS, Souza ER. Violência sob o olhar da saúde. A infrapolítica da contemporaneidade brasileira. Rio de Janeiro: Ed. Fiocruz; 2006. p.23-49.

2. Minayo MCS. A inclusão da violência na agenda da saúde: trajetória histórica. Ciênc saúde Colet. 2007;11(Sup.): 125967.

3. Deslandes SF. A violência como realidade e desafio aos serviços de saúde. In: Frágeis deuses: profissionais da emergência entre os danos da violência e a recriação da vida. Rio de Janeiro: Ed. Fiocruz.;2002. p.11-26.

4. Amaro MCP, Andrade SM, Garanhani ML. A Atuação do Serviço de Saúde na Violência sob o Olhar de Lideranças Comunitárias de Londrina (PR). Saúde Soc. 2008;17(3):171180.

5. Cyrino EG, Prearo AY, Dexan EB, Romanholi RMZ, Quarentei MS. A universidade na comunidade: Educação 
médica em transformação. Botucatu: NAP FMB UNESP, 2005.168p.

6. Carandina L, Almeida MAS. Dados demográficos e principais indicadores de saúde nas áreas de abrangência das Unidades de Saúde da rede básica do município de Botucatu/SP, no quinqüênio 2003 a 2007 - Botucatu em Dados 2008. Botucatu-SP, Brasil: UNESP, 2009.

7. Minayo MCS. O desafio do conhecimento: pesquisa qualitativa em saúde. 10 ed. São Paulo: Ed. Hucitec; 2007. 392p.

8. Souza ER, Ferreira AL, Santos NC. Concepções de docentes em relação ao manual sobre violência intrafamiliar. Rev Bras Edu Med, 2009;33(3):329-38.

9. Peduzzi M, Del Guerra DA, Braga CP, Lucena FS, Silva JAM. Atividades educativas de trabalhadores na atenção primária: concepções de educação permanente e de educação continuada em saúde presentes no cotidiano de Unidades Básicas de Saúde em São Paulo. Interface Comun Saúde Educ. 2009;13(30):121-134.

10. Imperatori G, Lopes MJM. Estratégias de Intervenção na Morbidade por Causas Externas: como atuam agentes comunitários de saúde? Saúde Soc. 2009;18(1):83-94.

11. Cavalcanti MLT. Prevenção da violência doméstica na perspectiva dos profissionais de saúde da família. Ciênc Saúde Colet. 1999;4(1):193-200.

12. Meirelles ZV, Gomez CM. Rompendo com a criminalidade: saída de jovens do tráfico de drogas em favelas na cidade do Rio de Janeiro. Ciênc Saúde Colet. 2009;14(5):1797-05.

13. Saliba O, Garbin CAS, Garbin AJI, Dossi AP. Responsabilidade do profissional de saúde sobre a notificação de casos de violência doméstica. Rev Saúde Pública. 2007;41(3):472-7.

14. Schraiber LB, Couto MTC, D'Oliveira AFLP, Pinho AA, Hanada H, Felicíssimo A et al. Características da violência física e/ou sexual entre mulheres usuárias de serviços de saúde da Grande São Paulo. Ciênc Saúde Colet.2003; 8(supl.1):149-152.

15. Vicente L M, Vieira EM. O conhecimento sobre violência de gênero entre estudantes de medicina e médicos residentes. Rev Bras Educ Med, 2009;33(1):63-71.

16. Deeke LP, Boing AF, Oliveira WF, Coelho EBS. A Dinâmica da Violência Doméstica: uma análise a partir dos discursos da mulher agredida e de seu parceiro. Saúde Soc. 2009;18(2):248-58.

17. Moreira SNT, Galvão LLLF, Melo COM, Azevedo GD. Violência física contra a mulher na perspectiva de profissionais de saúde. Rev Saúde Pública, 2008;42(6):1053-9.
18. Frenk J. La nueva salud pública. In: La crisis de la salud pública: reflexiones para el debate. Washington, DC: OPAS, 1992. p. 75-93 (Publicación Científica, 540).

19. Gomes R. A violência social em questão: referenciais para um debate em saúde pública. Rev. latinoam enferm, 1997;5(2):93-100.

20. Njaine K, Minayo MCS. A violência na mídia como tema da área da saúde pública: revisão da literatura. Ciênc Saúde Coletiva, 2004;9(1):201-211.

21. Minayo MCS. A Violência Social sob a Perspectiva da Saúde Pública. Cad Saúde Pública, 1994;10 (supl. 1):07-18.

22. Minayo MCS. Violência: um velho-novo desafio para a atenção à saúde. Rev Bras Educ Med, 2005;20(1):55-63.

23. Borsoi TS., Brandão ER, Cavalcanti MLT. Ações para o enfrentamento da violência contra a mulher em duas unidades de atenção primária à saúde no município do Rio de Janeiro. Interface Comunic Saúde Educ,2009;13(28):165-74.

24. D'Oliveira AFPL, Schraiber LB, Hanada H, Durand J. Atenção integral à saúde de mulheres em situação de violência de gênero - uma alternativa para a atenção primária em saúde. Ciênc Saúde Colet. 2009;14(4):1037-1050.

\section{CONTRIBUIÇÃO DOS AUTORES}

Cristiano Claudino Oliveira participou da concepção e elaboração do projeto, executou e transcreveu as entrevistas, realizou busca e leitura de referências bibliográficas, participou das discussões sobre os resultados encontrados e escreveu o texto do artigo. Margareth Aparecida Santini de Almeida participou da concepção e elaboração do projeto, da pesquisa de referências bibliográficas e das discussões sobre os resultados encontrados, utilizando a metodologia qualitativa. Como orientadora, realizou supervisão das atividades do discente e revisou a escrita do artigo. Ione Morita participou da concepção e elaboração do projeto, da pesquisa de referências bibliográficas e das discussões sobre os resultados encontrados, utilizando a metodologia qualitativa. Como orientadora, realizou a supervisão das atividades e revisou a escrita do artigo.

\section{CONFLITO DE INTERESSES}

Declarou não haver.

\section{ENDEREÇO PARA CORRESPONDÊNCIA}

\section{Cristiano Claudino Oliveira}

Rodovia Antônio Butgnoli, 10, apto.23 Bloco. A2 Cond.

Cidade Universitária

Rubião Júnior - Botucatu

CEP. 18618-000 SP

E-mail: cno@terra.com.br 